\title{
Linajes masculinos y su diversidad en comunidades Wichí de Formosa
}

RMA

Antropología Biológica

\author{
Virginia Ramallo ', María Rita Santos ', Marina Muzzio ${ }^{1,}$
María Brenda Motti ${ }^{1}$, Susana Salceda 2, Graciela Bailliet \\ Josefina María Brenda Motti ${ }^{1}$, Susana Salceda ${ }^{2}$, Graciela Bailliet ${ }^{1}$ \\ 1 Instituto Multidisciplinario de Biología Celular (IMBICE). \\ CICPBA-CCT-CONICET-La Plata. E-mail: gbailliet@imbice.org.ar \\ ${ }^{2}$ Laboratorio de Antropología Biológica, Museo de Ciencias Naturales, FCNyM, \\ Universidad Nacional de La Plata.
}

\begin{abstract}
Resumen
Durante el año 2005, se realizaron dos viajes de campaña a comunidades Wichí cercanas a las localidades de Ingeniero Juárez y Laguna Yema (provincia de Formosa, Argentina), como parte del proyecto multidisciplinario "De las historias étnicas a la prehistoria en el Gran Chaco". Partiendo del planteo metodológico de unidad poblacional, se obtuvieron datos genéticos en 93 muestras utilizando marcadores binarios y microsatélites del cromosoma $Y$, determinando haplogrupos y haplotipos masculinos. El haplogrupo Q1a3a, natural del continente americano, resultó mayoritario en ambas localidades (72,7 \% y 81,6\%). Los linajes moleculares se compararon con la diversidad de apellidos registrada y las posibles vinculaciones entre las comunidades Wichís se analizaron por redes "median joining", encontrando una variabilidad de linajes coherente con la distribución de las parcialidades del "complejo étnico Wichi" propuesto por Braunstein.
\end{abstract}

Palabras claves: Herencia genética, cromosoma Y, PCR, SNP, STR

Male lineages diversity in Wichí communities of Formosa province, Argentina

\begin{abstract}
During the year 2005, as part of the multidisciplinary project "Of the ethnic histories to the prehistory of the Gran Chaco", two field trips to the wichi communities nearing the locations of Ingeniero Juárez and Laguna Yema (Formosa province, Argentina) were made. From the methodological proposal of a population unit, genetic data in 93 samples, employing binary markers and microsatellites of the Y-chromosome were obtained, determining male haplogroups and haplotypes. The Q1a3a haplogroup, native of the American continent, resulted the most common in both locations (72,7\% and 81,6\%). The molecular lineages were compared with the registered surname diversity and the possible links between the wichi communities were analyzed through "median joining" networks, finding a lineage variability that is reasonable given the distribution of the partialities of the "wichi ethnic complex" proposed by Braunstein.
\end{abstract}

Keywords: Genetic heredity, Y chromosome, PCR, SNP, STR

Las poblaciones humanas pueden estudiarse a través de múltiples fuentes y aplicando diversas metodologías. El desarrollo tecnológico en el área de la biología molecular hizo posible acceder al interior de las células y conocer las diferencias poblacionales a nivel del ADN. De toda la información allí contenida, resulta en estos estudios de especial interés la porción no recombinante del cromosoma $Y$, dado que se trasmite como un bloque de padres a hijos varones. Su única fuente de variación es la mutación, es decir, la posibilidad de ocurrencia de un cambio que sea heredado a la generación siguiente. Como resultado encontramos, en diferentes porcentajes dentro de cada población particular, polimorfismos, formas alternas del cromosoma Y.

Para abordar esta diversidad se utilizan marcadores binarios. Pueden tratarse de cambios en una sola base de la secuencia de nucleótidos (SNP por sus siglas en inglés
"Single Nucleotide Polymorphism") o de la inserción o deleción de un grupo de bases. Una vez identificada la presencia o ausencia de cada marcador, se construyen haplogrupos y las relaciones entre ellos se representan en un árbol filogenético (Y Chromosome Consortium, 2002; Karafet et al., 2008). Según la nomenclatura acordada y normalizada hasta la fecha, cada haplogrupo se identifica con una letra, desde A hasta T (Figura 1).

Una de las aplicaciones más relevantes de esta herramienta es que permite asignar un origen geográfico a los distintos linajes presentes en las poblaciones actuales. Dentro del haplogrupo Q, un linaje se define por la mutación M3 (Underhill et al. 1996) y este sub-haplogrupo se considera exclusivo de América.

También pueden identificarse polimorfismos en microsatélites. Así se denominan las secuencias altamente 


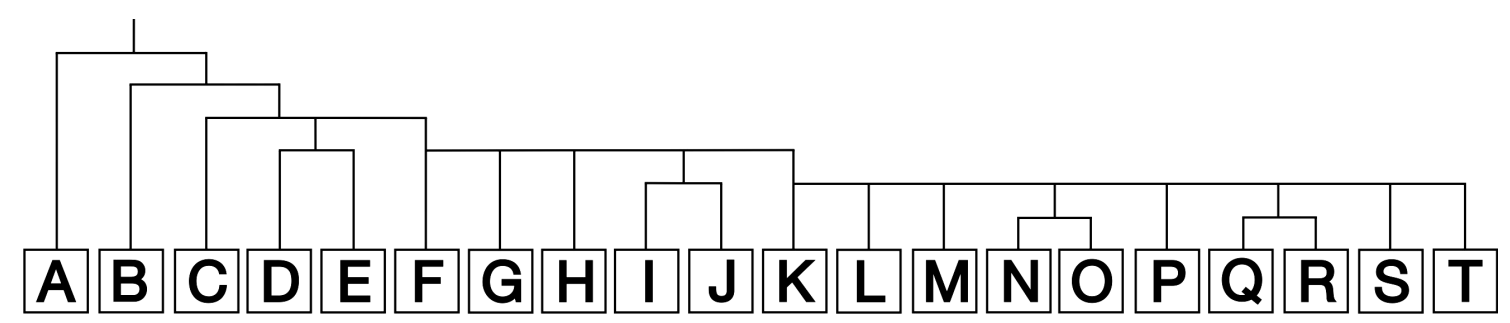

Figura 1: Síntesis de la filogenia de haplogrupos del cromosoma Y (Sobre YCC 2002 y Karafet et al., 2008)

repetitivas de nucleótidos en tandem o STR ("Short Tandem Repeat"). Las distintas variantes o alelos para cada microsatélite pueden determinarse contando la cantidad de veces que se repite el motivo-secuencia de ADN. Con un conjunto de siete marcadores puede lograrse una identificación individual. Estos datos son la base para construir haplotipos y los alelos que los definen tienen distribuciones diferenciales dentro de cada grupo étnico (Jobling y Tyler-Smith, 2003).

Por fuera del registro genético, los linajes se han establecido históricamente por la continuidad y herencia de los apellidos, poseer un mismo nombre podría representar ancestralidad común. En América, este sistema nomenclador es producto de una imposición colonial. En Argentina se emplea mayoritariamente el apellido paterno, recibiéndolo tanto las hijas como los hijos de una pareja. El cromosoma $Y$ se hereda de la misma manera, aunque sólo de varones a varones, de modo que los archivos escritos y las genealogías pueden relacionarse con los datos moleculares. Los matrimonios direccionales, la endogamia, las migraciones, la evangelización, los bautismos y la imposición y supresión de identidades son alguno de los factores que influyen en esta asociación entre linajes biológicos y culturales.

La exploración de la región del Gran Chaco comenzó tempranamente, pero la ocupación efectiva del territorio de Formosa está asociada a la expansión y consolidación de las fronteras del Estado Nacional a partir de 1884. Formosa adquiere su categoría de provincia recién en 1955 y sanciona su Constitución en 1957 (Beck, 1992, 1994). Ingeniero Juárez (Departamento Matacos) y Laguna Yema (Departamento Bermejo) se fundaron a comienzos del siglo XX como núcleos urbanos paralelos al tendido del ferrocarril y desde sus inicios, la composición poblacional fue multiétnica. Además de los grupos criollos ganaderos y las comunidades amerindias, la obra del tendido ferroviario atrajo inmigrantes europeos de diverso origen, como ucranianos, polacos o rusos. Al asentarse en estos centros emergentes, las familias Wichí siguieron pautas de nucleamiento por origen común o afinidades sociales.

Los grupos aborígenes del Gran Chaco experimentaron profundas transformaciones a muchos niveles, incluida una reducción notable en su demografía, especialmente violenta durante los años de las campañas militares. El deterioro de sus antiguos territorios y la sedentarización impuesta los llevó a la dependencia casi exclusiva del trabajo asalariado. Fueron forzosamente incorporados al circuito económico del país como mano de obra en las industrias madereras o azucareras, conformando los estratos sociales más bajos. Rodríguez Mir (2007) señala

\section{"...la propuesta que se fue forjando intentó la exclusión del indígena mediante la fusión o superación numérica, es decir, la dilución del indígena en inmensos contingentes de inmi- grantes europeos".}

Hoy es posible observar este mosaico de orígenes geográficos en las localidades de Formosa, la fracción amerindia representa un porcentaje elevado del total de habitantes de la provincia.

A partir de la reforma del año 1994, la Constitución Nacional establece el derecho de los Pueblos Indígenas a una educación bilingüe intercultural (artículo 75 inciso 17). En la región relevada, estas escuelas cuentan con una jornada de escolarización completa e incluyen un comedor. El alumnado es casi exclusivamente Toba o Wichí. Las clases están a cargo de docentes criollos y cuentan con un docente auxiliar o MEMA (Maestro Especializado en Modalidad Aborigen).

Los resultados presentados se produjeron en el marco del proyecto multidisciplinario de investigación "De las historias étnicas a la prehistoria en el Gran Chaco". Entendiendo al Gran Chaco como una unidad geohistórica, se estudia el presente regional en articulación con los registros del pasado. En el año 2005 se realizaron relevamientos entre comunidades Wichí de las ciudades de Laguna Yema e Ingeniero Juárez. La metodología de campo se basó en la articulación con tres escuelas locales: Escuela Nro. 421 Wichí Lako, de Laguna Yema, Escuela Nro. 521 Anexo El Quimil y Escuela Nro. 420 Misión Pozo Yacaré, éstas últimas dentro de la jurisdicción Ingeniero Juárez. Entre los objetivos bioantropológicos se incluía el monitoreo de la sanidad de la población infanto-adolescente: se tomaron un conjunto de parámetros biométricos para cada alumno, se confeccionó su ficha odontológica, el test de Ishihara de ceguera a los colores y la impresión de dermatoglifos dactilares y palmares. Para la recolección de muestras biológicas se contó con el aval y firma de un protocolo de consentimiento informado.

El propósito de este trabajo es conocer la cantidad de linajes masculinos presentes en las dos localidades, 
definiéndolos tanto a nivel de haplogrupo como de haplotipo y contrastar esta información con la diversidad de apellidos registrados, además de comparar la variabilidad genética entre las muestras de ambos conjuntos poblaciones.

\section{Materiales y Métodos}

Se analizaron 93 muestras masculinas (33 de Ingeniero Juárez, 60 de Laguna Yema), colectadas por salivación directa en tubos Falcon de 50 mililitros. Cada muestra fue identificada según un código numérico que remite a la localidad, al establecimiento educativo, al sexo y apellido del donante. Aquellas personas que comparten apellidos comparten un mismo subíndice en su código de almacenamiento.

La extracción de ADN se realizó mediante un preparado comercial (Nucleo Spin Tissue, Macherey-Nagel). La técnica de PCR (Polymerase Chain Reaction) se utilizó para amplificar los sitios de interés y los polimorfismos se determinaron por digestión enzimática en 8 marcadores: M3, M242, M207, M173, P27, M9, M89 y YAP (ver detalles y protocolo en Underhill et al. 1996, Seielstad et al. 2003, Su et al. 1999, Karafet et al. 1999, Hammer et al. 2001 y Hammer 1995). Mediante la misma técnica de PCR se estudió un conjunto de siete microsatélites: DYS 19, 389 I y 389 II, 390, 391, 392 y 393 (de Knijff 1997), estableciendo los alelos por electroforesis en acrilamida desnaturalizante.

Las frecuencias de haplogrupos y haplotipos se establecieron por conteo directo. Para estimar la diversidad génica (Nei 1987) se utilizó el programa ARLEQUIN 3.11 (Excoffier, Laval, Schneider 2005). El software NETWORK 4.5.1 (Bandelt et al. 1999 - http//:www. fluxus-engineering.com/sharenet.htm) se empleó para construir redes de haplotipos mediante el algoritmo "Median-Joining" o enlaces medios, que relaciona en forma parsimoniosa un conjunto de datos en una única red, basado en el modelo de mutación gradual (Kimura y Ohta 1978) Se consideraron aquí los siete sistemas de microsatélites pero, dado que los distintos alelos de cada locus poseen tasas mutacionales diferenciales, se asignaron pesos relativos a cada carácter, con valores entre 1 y 10. Se empleó la fórmula de estimación (Muzzio et al. 2008) a partir de los datos publicados en la base internacional YHRD (Willuweit et al. 2007).

\section{Resultados}

Se identificaron cinco haplogrupos, tal como se presentan en Tabla 1. En ambas localidades, el mayoritario fue Q1a3a, típico de poblaciones amerindias. Los porcentajes restantes incluyen linajes diferentes y minoritarios, todos de procedencia extra continental.

Para la tipificación de microsatélites, se emplearon exclusi-

\begin{tabular}{ccc}
\hline & Ing. Juárez & L. Yema \\
\hline $\mathrm{F}$ & $4(12,1 \%)$ & $6(10 \%)$ \\
$\mathrm{K}$ & $1(3 \%)$ & $1(1,6 \%)$ \\
$\mathrm{P}$ & $3(9 \%)$ & $1(1,6 \%)$ \\
Q1a3a & $24(72,7 \%)$ & $49(81,6 \%)$ \\
$\mathrm{R}$ & $1(3 \%)$ & $3(5 \%)$ \\
& & \\
\hline N & 33 & 60 \\
\hline Tabla 1. Frecuencias de haplogrupos
\end{tabular}

vamente los 73 varones Q1a3a. Dentro de esta selección, se registraron 43 apellidos diferentes. Para el análisis estadístico se siguieron dos criterios de exclusión sobre las muestras: ya sea por poseer datos incompletos (6 casos) o por existir un posible parentesco si tenían el mismo código de apellido, procedían de la misma localidad, de la misma escuela y presentaban los mismos marcadores genéticos (otros 6 casos). En la Tabla 2 se detallan los linajes encontrados y el número de individuos que los comparten. Se estableció un total de 28 haplotipos diferentes, que se distribuyen 10 en Laguna Yema (12 muestras), 11 en Ingeniero Juárez (12 muestras) y los 7

\begin{tabular}{|c|c|c|c|}
\hline$\frac{\frac{}{2}}{\frac{0}{0}}$ & & 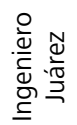 & 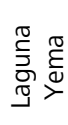 \\
\hline 0 & 13.13.30.24.10.14.13 & 2 & 9 \\
\hline $1 \mathrm{a}$ & 13.13 .30 .23 .10 .14 .13 & 1 & 1 \\
\hline $1 \mathrm{~b}$ & 13.13 .31 .24 .10 .14 .13 & 1 & 5 \\
\hline $1 \mathrm{c}$ & 13.13 .29 .24 .10 .14 .13 & 1 & 4 \\
\hline $1 \mathrm{~d}$ & 13.13 .30 .24 .10 .13 .13 & - & 1 \\
\hline $1 \mathrm{e}$ & 13.13 .30 .24 .10 .15 .13 & - & 2 \\
\hline $1 \mathrm{f}$ & 14.13.30.24.10.14.13 & - & 1 \\
\hline $2 a$ & 13.13.29.24.10.13.13 & 1 & 4 \\
\hline $2 b$ & 13.13 .31 .24 .10 .15 .13 & 2 & 4 \\
\hline $2 c$ & 13.14.31.24.10.14.13 & 1 & - \\
\hline $2 d$ & 13.13 .32 .24 .10 .14 .13 & 1 & - \\
\hline $2 \mathrm{e}$ & 13.12 .30 .24 .10 .14 .13 & 1 & - \\
\hline $2 f$ & 13.13.29.24.9. 14.13 & - & 1 \\
\hline $2 \mathrm{~g}$ & 13.13 .30 .24 .10 .14 .14 & - & 2 \\
\hline $2 \mathrm{~h}$ & 13.13.31.24.10.14.14 & - & 1 \\
\hline $3 a$ & 13.13 .33 .24 .10 .14 .13 & 1 & 1 \\
\hline $3 \mathrm{~b}$ & 13.13.32.24.10.13.13 & 1 & - \\
\hline $3 c$ & 13.13.29.24.10.15.13 & 2 & - \\
\hline $3 d$ & 13.13.31.24.10.16.13 & - & 1 \\
\hline $4 a$ & 13.13.34.24.10.14.13 & 1 & - \\
\hline $4 \mathrm{~b}$ & 15.13.31.24.11.14.13 & 1 & - \\
\hline $4 c$ & 13.11.30.23.11.14.13 & - & 1 \\
\hline $5 a$ & 13.13.31.23.10.11.13 & 1 & - \\
\hline $5 \mathrm{~b}$ & 13.11.30.23.11.14.12 & - & 1 \\
\hline $6 a$ & 15.14 .31 .23 .11 .14 .13 & 1 & - \\
\hline $6 \mathrm{~b}$ & 13.12.30.24.11.11.12 & 1 & - \\
\hline $6 c$ & 13.11.31.23.11.14.12 & - & 1 \\
\hline $7 \mathrm{a}$ & 13.14.31.23.10.16.15 & 1 & - \\
\hline$N$ & & 21 & 40 \\
\hline
\end{tabular}

Tabla 2. Distribución de haplotipos. Orden de marcadores DYS 19, DYS 389a, DYS 389b, DYS 390, DYS 391, DYS 392 y DYS 393, 0 Haplotipo fundador según Bianchi et al. (1998). Se destacan en negrita los linajes compartidos. 
restantes son comunes a ambas localidades (37 muestras).

En 1998, Bianchi y colaboradores analizaron 89 muestras Q1a3a de diferentes poblaciones aborígenes e identificaron un linaje que proponen como uno de los posibles fundadores ancestrales para América. Este mismo haplotipo, señalado como haplotipo 0 en la Tabla 2, resultó el mayoritario en las comunidades Wichí y constituye el nodo central en las redes, mientras que los restantes linajes más frecuentes se ubican a uno y dos pasos mutacionales.

En la tabla 3 se comparan las frecuencias alélicas entre poblaciones. De las muchas variantes posibles para cada marcador, una resultó siempre mayoritaria. Con excepción de DYS 390, en todos los sistemas se encontraron alelos exclusivos de una u otra población. DYS 389 II y DYS 392 son los que presentan niveles más altos de diversidad (0.785/0.647 y 0.673/0.483 para Ingeniero Juárez y Laguna Yema respectivamente), dato que concuerda con otros estudios previos sobre grupos aborígenes del Gran Chaco (Bianchi et al. 1998; Demarchi y Mitchell 2004)

En promedio, Ingeniero Juárez presenta una diversidad alélica mayor: $3.28 \pm 1.49$ comparando con $3 \pm 1.07$ en Laguna Yema. Las poblaciones tampoco resultaron

\begin{tabular}{|c|c|c|}
\hline Alelos & I. Juárez & L.Yema \\
\hline \multicolumn{3}{|l|}{ DYS 19} \\
\hline 13 & 0.90 & 0,97 \\
\hline 14 & 0 & 0.03 \\
\hline 15 & 0.10 & 0 \\
\hline \multicolumn{3}{|c|}{ DYS 389 I } \\
\hline 11 & 0 & 0.08 \\
\hline 12 & 0.10 & 0 \\
\hline 13 & 0.76 & 0.92 \\
\hline 14 & 0.14 & 0 \\
\hline \multicolumn{3}{|c|}{ DYS 389 ॥ } \\
\hline 29 & 0.24 & 0.22 \\
\hline 30 & 0.20 & 0.45 \\
\hline 31 & 0.38 & 0.30 \\
\hline 32 & 0.09 & 0 \\
\hline 33 & 0.05 & 0.03 \\
\hline 34 & 0.04 & 0 \\
\hline \multicolumn{3}{|c|}{ DYS 390} \\
\hline 23 & 0.20 & 0.90 \\
\hline 24 & 0.80 & 0.10 \\
\hline \multicolumn{3}{|c|}{ DYS 391} \\
\hline 9 & 0 & 0.02 \\
\hline 10 & 0.86 & 0.90 \\
\hline 11 & 0.14 & 0.08 \\
\hline \multicolumn{3}{|c|}{ DYS 392} \\
\hline 11 & 0.10 & 0 \\
\hline 13 & 0.09 & 0.12 \\
\hline 14 & 0.57 & 0.62 \\
\hline 15 & 0.19 & 0.15 \\
\hline 16 & 0.05 & 0.11 \\
\hline \multicolumn{3}{|c|}{ DYS 393} \\
\hline 12 & 0.05 & 0.05 \\
\hline 13 & 0.90 & 0.87 \\
\hline 14 & 0 & 0.08 \\
\hline 15 & 0.05 & 0 \\
\hline$N$ & 21 & 40 \\
\hline
\end{tabular}

Tabla 3. Frecuencias alélicas. Las frecuencias mayores se destacan en negrita.

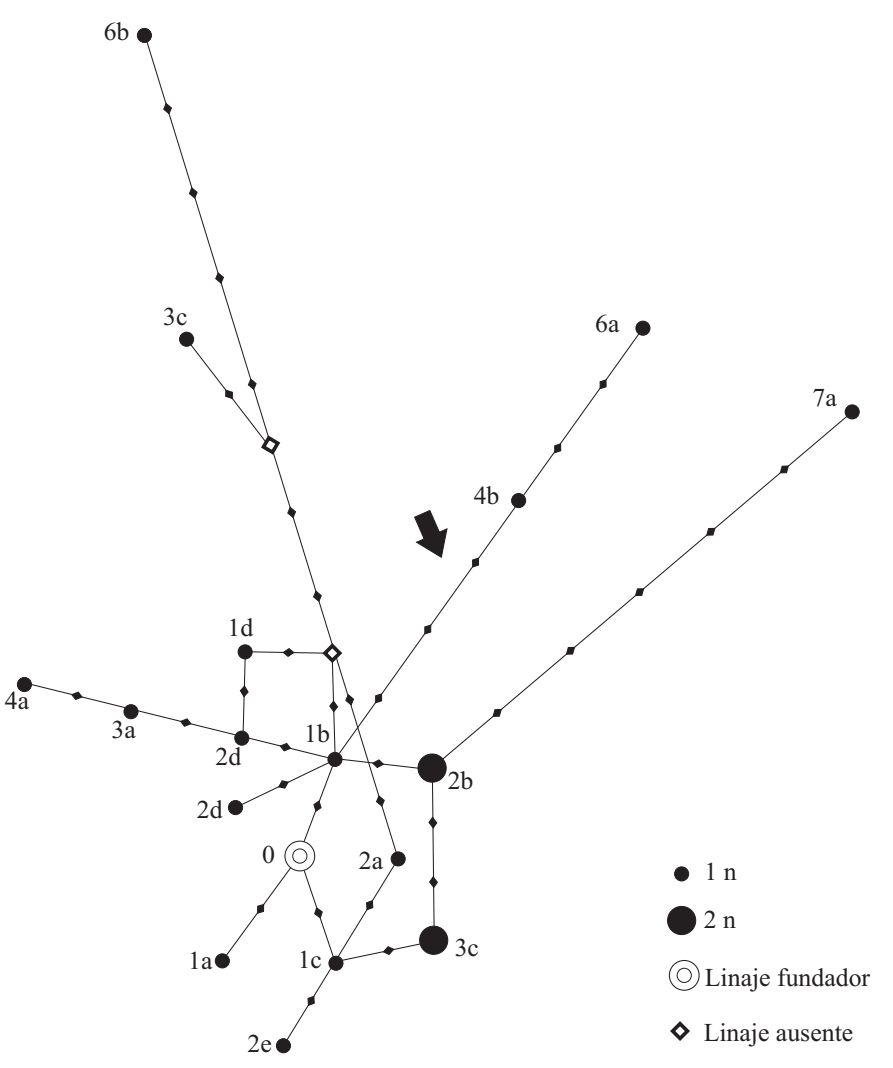

Figura 1. Red de haplotipos Ingeniero Juárez (código de haplotipos en Tabla 2)

homogéneas en el rango alélico (la diferencia entre el número máximo y mínimo de repetidos), siendo $2.7 \pm 1.6$ para Ingeniero Juárez y $2.3 \pm 1.3$ para Laguna Yema. En la Tabla 4 se presentan los porcentajes de los linajes agrupados según la cantidad de pasos que los separan del fundador o haplotipo 0 , que está representado por 11 varones (18\% del total). Si bien en cada localidad se identificaron linajes muy divergentes, con hasta 7 pasos mutacionales de distancia, éstos representan los menores valores. Más de la mitad tienen sólo uno o dos cambios en relación al haplotipo modal, siendo las muestras de Ingeniero Juárez las que acumulan más cambios.

En las redes "median-joining" obtenidas, los linajes que están más relacionados por un mismo ancestro se reúnen en un mismo nodo. Las figuras 1 y 2 presentan los resultados intrapoblacionales de Ingeniero Juárez y Laguna Yema y la figura 3 la red total con los 61 varones relevados, considerando todos los sistemas de microsatélites. El tamaño de los círculos es proporcional a la cantidad de

\begin{tabular}{ccc}
\hline PM & I. Juárez & L.Yema \\
\hline 0 & $2(9,5 \%)$ & $9(22,5 \%)$ \\
1 & $3(14,3 \%)$ & $14(35 \%)$ \\
2 & $6(28,6 \%)$ & $12(30 \%)$ \\
3 & $4(19 \%)$ & $2(5 \%)$ \\
4 & $2(9,5 \%)$ & $1(2,5 \%)$ \\
5 & $1(0,05 \%)$ & $1(2,5 \%)$ \\
6 & $2(9,5 \%)$ & $1(2,5 \%)$ \\
7 & $1(0,05 \%)$ & 0 \\
\hline
\end{tabular}

Tabla 4. Distribución de haplotipos en distancia con el ancestro. PM Pasos mutacionales 


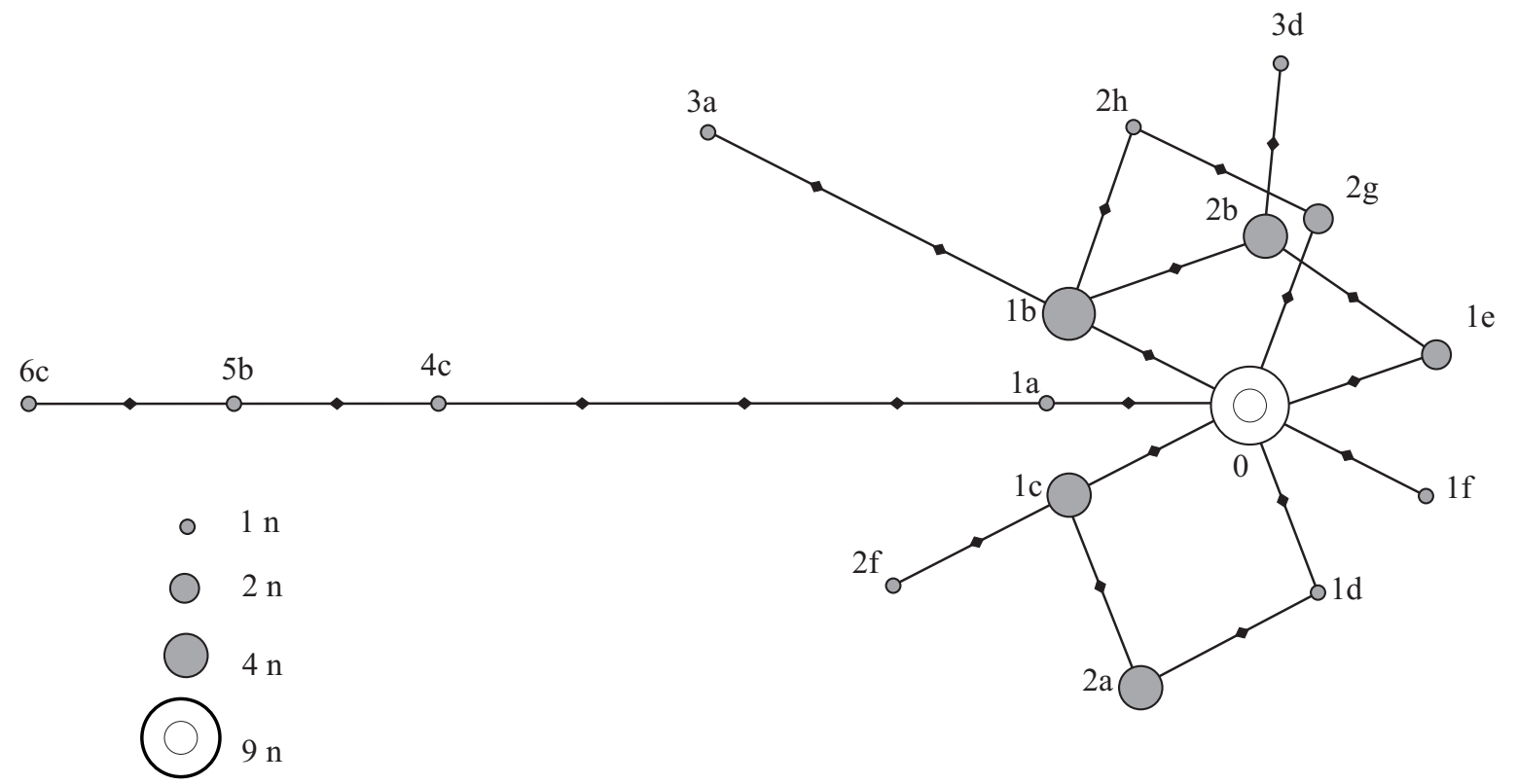

Figura 2. Red de haplotipos Laguna Yema

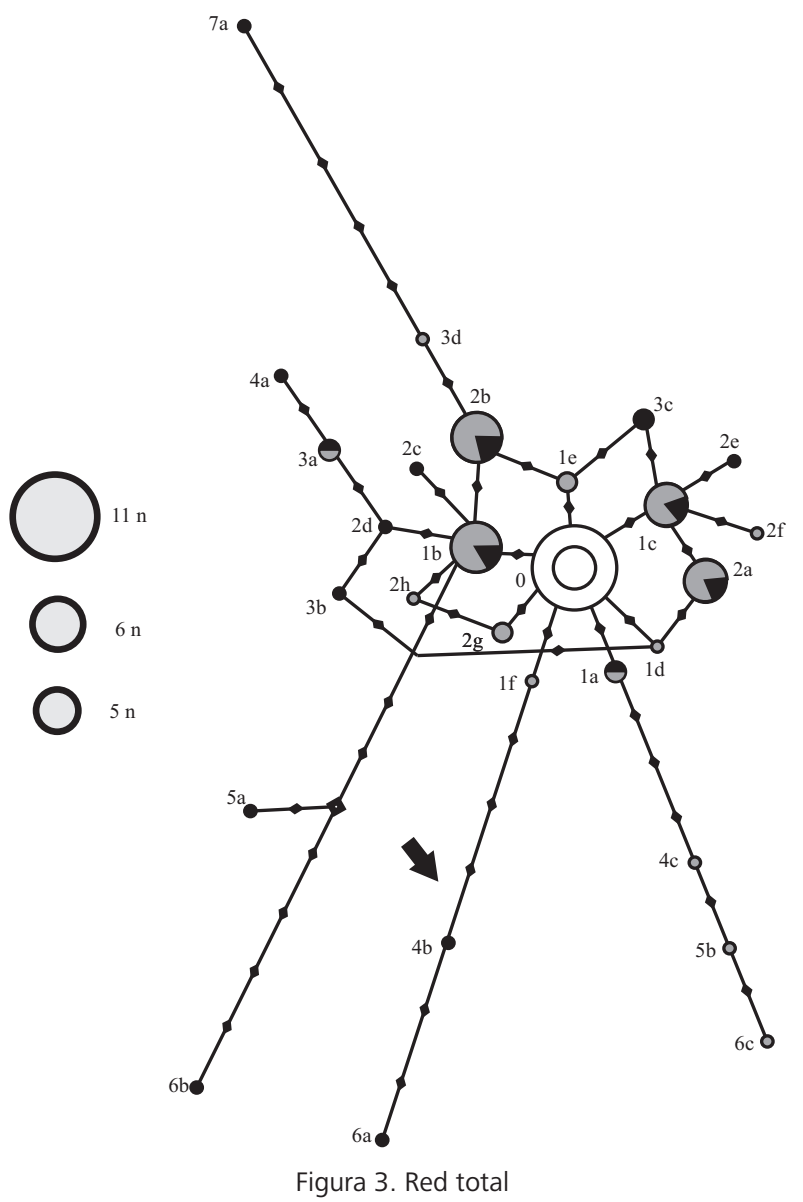

individuos que comparten el linaje. En las figuras 1 y 3 se señalan con una flecha los haplotipos que presentaron el alelo 15 para el sistema de microsatélite DYS 19, una característica exclusiva de Ingeniero Juárez

Al relacionar estos datos moleculares con los registros nominales, encontramos que 27 apellidos son únicos de Laguna Yema, 12 de Ingeniero Juárez y 2 son comunes a ambas localidades. Como ya se mencionara, una muestra se retiraba del análisis cuando dos donantes compartían datos de procedencia, apellido y haplotipo. Resulta entonces notable que esta redundancia se registrara en sólo 6 casos, dada la poca diversidad de nombres en relación al tamaño muestral. De las 61 muestras, sólo 18 varones tienen una correspondencia completa entre su apellido y su cromosoma Y. Los 14 apellidos que comprenden más de un linaje se denominan polifiléticos, en tanto los 10 haplotipos que incluyen más de un apellido se denominan linajes trans-apellido.

En estos apellidos diversos a nivel molecular, la transmisión del cromosoma Y siguió una pauta diferente. Dado que no se cuenta con un relevamiento genealógico completo, no es posible saber si este polifiletismo se debe a la herencia del apellido del progenitor femenino o responde a otras causas, como posibles errores de grafía en el Registro Civil.

\section{Discusión y Conclusiones}

Las poblaciones analizadas aquí se incluyen dentro de un macro entorno, en una región conocida como Gran Chaco. Es una llanura de aproximadamente un millón de kilómetros cuadrados, situada en el ámbito de las Tierras Bajas Sudamericanas, que abarca parte de Brasil, Bolivia y Argentina. Los ríos Pilcomayo, Bermejo y sus afluentes tienen una dinámica estacional que determina paisajes aluvionales. Han experimentado desbordes y también notables retrocesos en su cauce. Esto, sumado a las marcadas diferencias entre la estación seca y la húmeda condicionó el establecimiento de grupos humanos en la zona, siendo considerada como una de las regiones más tardíamente ocupadas del continente (Calandra y Salceda 2004). 
En este escenario se asentaron y desarrollaron diferentes pueblos de economía cazadora-recolectora, que ensayaban grandes desplazamientos en el terreno según la disponibilidad de recursos. En el citado trabajo de Demarchi y Mitchell (2004) sobre grupos aborígenes de la región (Wichí de Formosa, Toba y Pilagá de Chaco) sostienen que, dada la variedad de haplotipos encontrados, los primeros grupos humanos que se instalaron en el Gran Chaco eran genéticamente diversos. El nomadismo desarrollado durante siglos hizo que la deriva génica actuara poderosamente en las modificaciones posteriores de esa variedad. Estos continuos procesos de cambios manifiestan una significativa aceleración a partir de la conquista española y sus consecuencias pueden analizarse tanto a nivel inter como intragrupal.

Para el caso de las comunidades formoseñas de nuestro estudio, los datos muestran que existe, a nivel de diversidad de cromosoma $Y$, una distribución modal compartida, pero también variables regionales. De los 28 haplotipos identificados en este trabajo (Ver Tabla 2), solo son comunes el fundador y 6 linajes adyacentes. Hay 10 linajes Wichí exclusivos de Laguna Yema y 11 de Ingeniero Juárez, dos localidades distantes a 70 kilómetros. En ésta última se registró también una diversidad alélica mayor, con algunas variantes señaladas en la literatura

\begin{tabular}{lccc}
\hline & I. Juárez & L. Yema & Total \\
\hline Apellidos & 14 & 29 & 43 \\
-Linaje único & 10 & 8 & 18 \\
-Polifiléticos & 4 & 10 & 14 \\
$N$ & 21 & 40 & 61 \\
\hline
\end{tabular}

Tabla 5. Haplotipos y apellidos

como raras por su baja frecuencia, como el alelo 15 del sistema DYS 19 (Carvalho-Silva et al. 1999, Bianchi et al. 1998, Ruiz-Linares et al. 1999, Demarchi y Mitchell 2004). Posee un rango alélico sensiblemente mayor al de Laguna Yema. Cuenta con el menor tamaño muestral, pero la mayor cantidad de haplotipos, además de las mayores divergencias en relación al linaje fundador por acumulación de pasos mutacionales. Para tratarse de dos conjuntos de la misma población amerindia, se comportan con un interesante nivel de singularidad.

Tal vez ese principio de homogeneidad sea un concepto útil para ciertos análisis, pero lejano a la esencia de los datos. En todos los párrafos anteriores, se ha empleado el término Wichí sin profundizar en su origen. Según Braunstein (2006), se utiliza para denominar a los indígenas que habitan un área triangular del Gran Chaco de aproximadamente $100.000 \mathrm{~km}^{2}$ y abarca el noroeste de la provincia de Formosa y parte de Salta y Chaco. Se trata de más de 40.000 personas que hablan variantes o

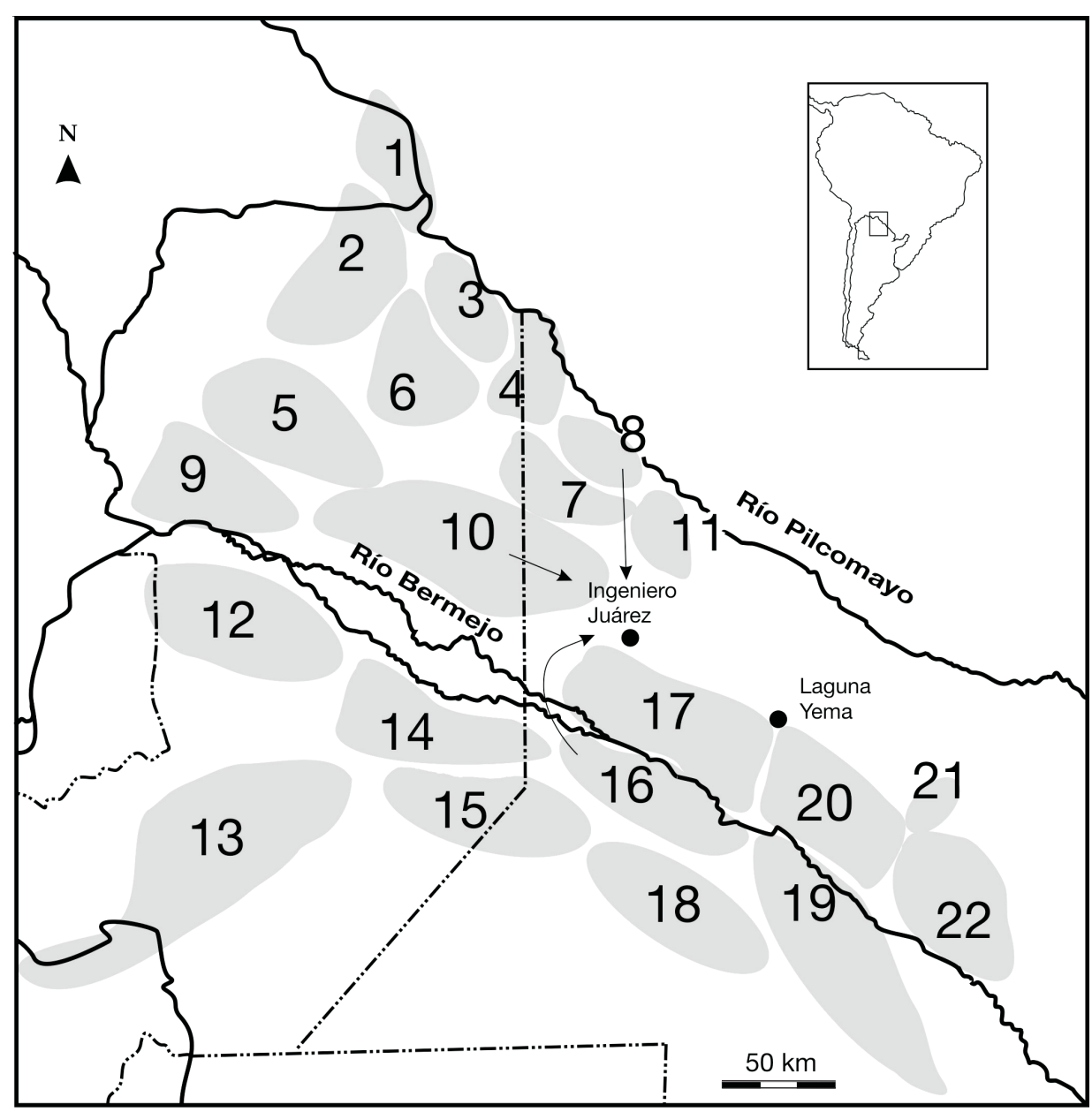

Figura 2: Carta étnica de los pueblos Wichí (Según Braunstein 2006). 
dialectos de la "lengua mataca" (Braunstein 2006) pero que no constituirían un único pueblo. Hasta comienzos del siglo $X X$, los Wichí vivían en grupos de familias extendidas, estas bandas se desplazaban cada una en forma regular por un territorio diferente y reconocido por otras bandas. Las unidades mantenían entre sí relaciones de alianza, expresadas en intercambios matrimoniales. Braunstein identifica a estos grupos de alianza como unidades sociopolíticas

\section{"(...) que pueden llamarse 'pueblos', 'tribus'o "naciones'" de modo que cuando se considera a los Wichí "(...) en realidad se trata de un grupo con afinidades lingüísticas formado por varios pueblos o naciones (...) lo que estaríamos incli- nados a denominar 'complejo étnico"}

Sus integrantes poseen un sistema conceptual que permite individualizar cada segmento tanto por su ubicación en el espacio (por proximidad a las corrientes fluviales y su posición a lo largo del curso de agua) como por denominaciones que son nombres propios. Basándose entonces en gentilicios, topónimos y criterios de afinidad, Braunstein y Dell'Arciprete (1999) presenta una carta gráfica de los territorios que las distintas unidades Wichí ocupaban hacia 1900, fecha estimada del comienzo del proceso de sedentarización. Como puede verse en la figura 2, dentro de la provincia de Formosa, Ingeniero Juárez y Laguna Yema se ubican en sectores de contacto entre antiguos territorios y desde su fundación, han recibido contingentes poblacionales de distintos focos. Estos movimientos migratorios y su polaridad están señalados con flechas.

Los linajes identificados en las muestras y sus frecuencias permiten suponer que el patrimonio genético de estos grupos posee una historia común, pero con particularidades locales que se mantienen en el tiempo. La distribución actual de haplotipos no sería azarosa, sino producto de procesos históricos de estructuración poblacional. Los patrones en la selección de pareja brindan un marco para comprender dichos procesos. La unidad social más pequeña es la familia, que habita una misma vivienda e incluye a la pareja progenitora y todos sus hijos solteros, además de las parejas recién formadas de las hijas, que ocuparán durante un tiempo la misma residencia y contribuirán al mismo foco económico. La nueva familia puede separarse cuando nacen sus hijos, pero permanecen cerca y pertenecen al mismo grupo residencial de máxima cooperación (Braunstein 2003). Los pueblos Wichí tienen en común un sistema de parentesco bilateral, se reconocen como parientes los integrantes de los linajes materno y paterno, con tendencia a la uxorilocalidad -la residencia junto al grupo familiar de la mujer-. Los nuevos matrimonios se forman siguiendo una serie de pautas rígidas de exogamia entre parientes cercanos y endogamia entre grupos locales. Las distintas frecuencias regionales de linajes masculinos pueden interpretarse como mayor movilidad de los hombres, que se mudan al establecer matrimonio, pero siempre dentro de un grupo reconocido y distinto de sus vecinos.

La Plata, 11 de agosto de 2009

\section{Agradecimientos}

Financiación: FONCYT, CIC, CONICET y Fundación Antorchas. Agradecemos especialmente a todos los donantes, al Dr. Darío A. Demarchi, al Dr José Braunstein, a las autoridades del CEDEVA (Centro de Validación y Tecnologías Agropecuarias) de Laguna Yema y a los directivos de las escuelas relevadas.

\section{Bibliografía}

Bandelt, H.J., P. Forster, A. Röhl. 1999. Median-joining networks for inferring intraspecific phylogenies. Molecular Biology Evolution 16:37-48

Beck, H. 1992. La ocupación del espacio en el oeste chaqueño y formoseño desde la provincialización de los territorios (1950-1983). Cuadernos de Geohistoria Regional N² 25.

Beck, H. 1994. Relaciones entre blancos e indios en los territorios nacionales de Chaco y Formosa 1885-1950. Cuadernos de Geohistoria Regional № 29.

Bianchi, N.O., C. Catanesi, G. Bailliet, V. Martínez-Marignac, C. Bravi, L. Vidal-Rioja, R. Herrera y J. S. LópezCamelo. 1998. Characterization of ancestral and derived Y-chromosome haplotypes of New World native populations. American Journal of Human Genetic 63:1862-1871.

Braunstein J. y A. Dell'Arciprete. 1999 Carta étnica de los pueblos Wichí Mapa de ubicación de variantes dialectales. Las palabras de la gente: Alfabeto unificado para wichi Ihamtes. Proceso de consulta y participación. 2000 Buliubasich, C., Nicolás Drayson y Silvia Molina de Bertea (Editores). CEPIHA, Facultad de Humanidades. UNSA.

Braunstein, J. 2006. El signo del agua. Formas de clasificación étnica Wichí. Definiciones étnicas, organización social y estrategias políticas en el Chaco y la Chiquitania Editora: Isabelle Combes. Actes et Memoire de I'Institute Français d'Etudes Andines 11

Braunstein, J. 2003. Organización social: propiedad y distribución entre los Wichí del noroeste de la provincia de Formosa. http://www.programadirli.com/Documentos/ Consulta:Brauntein.doc (Última consulta: 12/08/2009)

Calandra, H. y S. Salceda. 2004. El territorio y sus ocupantes: ¿qué, quienes, cómo y cuándo? Folia Histórica del Nordeste. Vol. 15: 107-128.

Carvalho-Silva, D.R., F. R. Santos, M. H. Hutz, F. M. Salzano y S. D. J. Peña. 1999. Divergent human Y-chromosome 
microsatellite evolution rates. Journal of Molecular Evolution. 49(2):204-214.

Demarchi, D. y J. Mitchell. 2004. Genetic structure and gene flow in Gran Chaco populations of Argentina: evidence from Y-chromosome markers. Human Biology, 76 (3): 413-429.

de Knijff, P., M. Kaiser, A. Caglia, D. Corach, N. Fretwell, C. Gehrig y G. Graziosi. 1997. Chromosome Y microsatellites: population genetic and evolutionary aspects. International Journal of Legal Medicine 110: 134-140.

Excoffier L., G. Laval y S. Schneider. 2005.Arlequin (version 3.0): an integrated software package for population genetics data analysis, Evolutionary Bioinformatics Online $11: 47-50$.

Hammer, M.F. 1995. A recent common ancestry for human Y chromosomes. Nature 378: 376-378.

Hammer, M.F., T. M. Karafet, A. J. Redd, H. Jarjanazi, S. Santachiara-Benerecetti, H. Soodyall y S. L. Zegura. 2001. Hierarchical patterns of global human Y-chromosome diversity. Molecular Biology and Evolution 18: 1189-1203.

Jobling, M. y C. Tyler-Smith. 2003. The human $Y$ chromosome: an evolutionary marker comes of age. Nature. Vol 4:598-612.

Karafet, T.M., S. L. Zegura, O. Posukh, L. Osipova, A. Bergen, J. Long, D. Goldman, W. Klitz, S. Harihara, P. de Knijff, V. Wiebe, R. C. Griffiths, A. R. Templeton y M. F. Hammer. 1999. Ancestral Asian source(s) of new world Y-chromosome founder haplotypes. American Journal of Human Genetic. 64:817-831.

Karafet, T.M., F. L. Mendez, M. B. Meilerman, P. A. Underhill, S. L. Zegura y M. F. Hammer. 2008. New binary polymorphisms reshape and increase resolution of the human Y chromosomal haplogroup tree. Genome $R e^{-}$ search. 18:830-838.

Kimura, M. y T. Ohta. 1978. Stepwise mutation model and distribution of allelic frequencies in a finite population Proceedings of the National Academy of Sciences 75 (6): 2868-2872.

Muzzio, M., V. Ramallo, J. E. Dipierri, E. L. Alfaro, J. M. B. Motti, S. Salceda, N. O. Bianchi y G. Bailliet.
2008. Patrones de similitud y diferenciación de linajes masculinos nativo-americanos en el Norte Argentino. Actas del X Congreso de la Asociación Latinoamericana de Antropología Biológica. http://www.xalab.fcnym.unlp. edu.ar/index.php-action=cIGENEPOBII.htm\#5 (Última consulta: 12/08/2009).

Nei, M. 1987. Molecular Evolutionary Genetics. New York: Columbia University Press.

Rodríguez Mir, J. 2007. El Chaco argentino como región fronteriza. Límites territoriales, guerras y resistencia indígena. Hispania Nova. Revista de Historia Contemporánea, $\mathrm{n}^{\circ} 7$.

Ruiz-Linares, A., D. Ortíz-Barrientos, M. Figueroa, N. Mesa, J. G. Múnera, G. Bedoya, I. D. Vélez, L. F. García, A. Pérez-Lezaun, J. Bertranpetit, M. W. Feldman y D. B. Goldstein. 1999. Microsatellites provide evidence for $Y$ chromosome diversity among the founders of the New World. Proceedings of the National Academy of Sciences 96 (6): 312-317.

Seielstad, M, Y. Nadira, N. Singh, P. Underhill, P. Oefner, P. Shen y R. Spencer Wells. 2003. A novel Y- chromosome variant puts an upper limit on the timing of first entry into the Americas. American Journal of Human Genetic, 73:000.

Su, B., J. Xiao, P. Underhill, R. Deka, W. Zhang, J. Akey, W. Huang, D. Shen, J. Luo, J. Chu, J. Tan, P. Shen, R. Davis, L. Cavalli-Sforza, R. Chakraborty, M. Xiong, R. Du, P. Oefner, Z. Chen y J. Lin. 1999. Y-chromosome evidence for a northward migration of modern human into eastern Asia during the last ice age. American Journal of Human Genetic. 65:1718-1724.

The Y Chromosome Consortium. 2002. A nomenclature system for the tree of human Y-chromosomal binary haplogroups. Genome Research. 12:339-348.

Underhill, P.A., J. Jin, R. Zemand, P.J. Oefner y L. CavalliSforza. 1996. A pre-columbian Y chromosome-specific transition and its implications for human evolutionary history. National Academy of Science 93:196-200.

Willuweit, S. y L. Roewer. 2007. Y chromosome haplotype reference database (YHRD): Update. Forensic Science International: Genetics 1(2), 83-7. 